\title{
Memória dos Troncos Velhos: um Estudo sobre Memória Social entre Ciganos
}

\section{Memory of Troncos Velhos: a Study on Social Memory among Gypsies}

\author{
Mariana Bonomo ${ }^{1}$ (orcid.org/0000-0002-3919-3976) \\ Grecy Kelle de Andrade Cardoso² (orcid.org/0000-0002-6384-3545) \\ Thais Silvestre Batista ${ }^{3}$ (orcid.org/0000-0003-2087-1578) \\ Rovena Milbratz Martins ${ }^{4}$ (orcid.org/0000-0001-6090-2151) \\ Fatima Tolentino da Silva ${ }^{5}$ (orcid.org/0000-0003-1657-4693)
}

\begin{abstract}
Resumo
O presente estudo teve como objetivo analisar as memórias práticas entre membros de uma comunidade cigana do estado do Espírito Santo, com cultura territorial seminômade, tradição oral e domínio linguístico do kaló. Foram realizados registros de informações em diários de campo e entrevistas individuais e em profundidade com cinco homens e cinco mulheres, com idades acima de 50 anos, integrantes das primeiras gerações da comunidade. Foi utilizado instrumento com roteiro semiestruturado explorando temas salientes à vida do grupo. As narrativas obtidas foram sistematizadas com o auxílio da classificação hierárquica descendente, procedida por meio do Programa Alceste. Entre os principais resultados encontrados, destacam-se as "relações de gênero e práticas cotidianas", "tradições e costumes" e "transformações em curso". Espera-se que o desenvolvimento deste estudo possa contribuir para ampliar o corpo de conhecimento produzido acerca da população cigana a partir de suas próprias narrativas.
\end{abstract}

Palavras-chave: Ciganos. Grupo étnico. Memória social. Identidade social.

Abstract

1 Universidade Federal do Espírito Santo, Vitória, Brasil. E-mail: marianadalbo@gmail.com.

2 Universidade Federal do Espírito Santo, Vitória, Brasil. E-mail: grecy.kelle@gmail.com.

3 Universidade Federal do Espírito Santo, Vitória, Brasil. E-mail: thaissbatista@hotmail.com.

4 Universidade Federal do Espírito Santo, Vitória, Brasil. E-mail: rovena_milbratz@hotmail.com.

5 Universidade Federal do Espírito Santo, Vitória, Brasil. E-mail: fafa_fatima1972@yahoo.com.br. 
The present study aimed to analyze the practical memories among members of a gypsy community from the State of Espírito Santo, with semi-nomadic territorial culture, oral tradition and mastery of language karó. Information records were made in field diaries and individual and in-depth interviews with five men and five women, aged over 50 years old, who were members of the first generations of the community. An instrument with a semi-structured script was used, exploring themes relevant to the group's life. The narratives obtained were systematized with the aid of the descending hierarchical classification, proceeding through the Programa Alceste. Among the main results found, "gender relations and everyday practices", "traditions and customs" and "ongoing transformations" stand out. It is hoped that the development of this study may contribute to expand the body of knowledge produced about the gypsy population from their own narratives.

Keywords: Gypsies. Ethnic group. Social memory. Social identity. 


\section{Introdução}

Evidências sobre a diáspora cigana datam de aproximadamente 1.000 anos, apesar da falta de dados oficiais e de consenso na historiografia cigana (Fonseca, 1996). Essa incerteza sobre a origem dos ciganos tem provocado o desenvolvimento de pesquisas que visam compreender a história dos ciganos e a relação entre as diferentes etnias que compõem esse povo. Atualmente, a partir de estudos linguísticos, a teoria mais aceita é a de que os ciganos teriam migrado para a Europa, aproximadamente, no ano 1000, com êxodo migratório a partir da Índia. Ainda existem questionamentos a respeito de como e onde isso ocorreu, mas acredita-se que, provavelmente, os ciganos saíram de diferentes partes da Índia, em diversas ondas migratórias ao longo dos anos, se dispersando por praticamente todas as territorialidades do globo (Acton \& Mundy, 1997; Moonen, 2011).

Os ciganos são um povo que se apresenta de forma heterogênea, sendo composto por diversos grupos, com diferentes línguas, normas, costumes e tradições (Ravnbøl, 2010). Considerando a composição da etnia cigana na formação populacional brasileira, três grandes segmentos podem ser destacados: os Rom, ou Roma, predominantes nos países balcânicos e no leste europeu, que migraram para outros países da Europa e para as Américas; os Sinti, também encontrados na Alemanha, Itália e França, onde são conhecidos como manouch; e os Calon ou Kalé, que seriam os ciganos ibéricos, vivem em Portugal e na Espanha, e foram deportados ou migraram para outros países da Europa e América do Sul a partir do século XVI (Andrade Júnior, 2013; Teixeira, 2008).

A perseguição aos grupos ciganos começou logo nos primeiros anos, quando migraram para o continente europeu. Segundo Moonen (2011), apesar de, em um primeiro momento, os europeus terem aceitado a presença dos ciganos com relativa tolerância, no decorrer dos anos, esse quadro mudou drasticamente, pois os ciganos passaram a ser vistos como um mal que deveria ser eliminado e muitas políticas anticiganas foram criadas para promover o banimento e extermínio dessa população (Kende, Hadarics \& Lášticová, 2017). Uma das políticas instituídas era a deportação, prática que fez com que muitos ciganos viessem para o Brasil, onde continuaram a ser perseguidos e excluídos (Brasil, 2013).

Estudos recentes (Andrade Júnior, 2013; Kende et al., 2017; Powell \& Lewer, 2017) revelam um panorama geral do modo como a sociedade tem se relacionado com o povo cigano, incluindo a elaboração de leis, decretos, obras artísticas e representações sociais sobre eles, e evidenciam que a sociedade ainda se recusa a aceitar os ciganos como parte dela, mantendo arranjos sociais que os colocam em um lugar marginal. Essas exclusões, perseguições e segregação social que os povos ciganos têm sofrido há vários séculos, ainda hoje orientam sua organização territorial, tanto nos grupos em situação de nomadismo quanto entre aqueles que estão em processo de fixação nos centros urbanos (Batista \& Medeiros, 2015; Silva, 2012; Vaz, 2009). Conforme salienta Miranda (2011, p. 33), historicamente, 
As cidades passaram então a impelir os ciganos para os espaços mais afastados, longe da dinâmica urbana. Os ciganos possivelmente ocupavam os espaços mais insalubres das cidades. Não que eles se opusessem ao conforto e à higiene, mas sim ao que vinha atrelado a tudo isso: o cerceamento à liberdade de movimentação e o controle de suas ações.

Como apontado, ao longo da história, o povo cigano foi excluído de diversas maneiras e, ainda hoje, a realidade cotidiana em que os povos ciganos se encontram é permeada por miséria e exclusão, muito diferente do que aparece no imaginário popular (Ferrari, 2006). Entre os inúmeros desafios identificados para a promoção de direitos basilares da população cigana, diversos estudos evidenciam a construção de imagens negativamente valoradas sobre eles no pensamento social (Lermo, Román, Marrodán \& Mesa, 2006). Em Sergipe, por exemplo, Carvalho, Lima, Faro e Silva (2012) mostram que as representações sociais dos ciganos são objetivadas por estereótipos negativos, sendo representados como diferentes, criminosos e briguentos. Outro estudo, realizado na grande Vitória - ES (Bonomo, Faria, Souza \& Brasil, 2012), aponta para a formação do campo representacional sobre essa população a partir de ambiguidades: são vistos como povo alegre, $d a$ dança e de roupas coloridas, despertando sentimentos de curiosidade, encantamento e admiração; mas também como um grupo que rouba e trapaceia, provocando insegurança, medo e mal-estar entre não ciganos.

Essa visão distorcida a respeito dos povos ciganos pode estar relacionada com a falta de estudos a respeito da sua condição de vida, tanto no passado quanto no presente. A historiografia mundial e, em especial a brasileira muito pouco se debruçou sobre esse povo, que, apesar de antigo, é pouco compreendido. Segundo Teixeira (2008), das poucas vezes em que os ciganos foram alvo de registros e estudos sistemáticos, nunca houve qualquer interesse sobre como eles próprios viam sua cultura.

Tendo como panorama o exposto, e sabendo que os ciganos são uma comunidade de tradição oral, defende-se a importância de estudos sobre a sua história, mas, sobretudo, sobre uma história contada por eles próprios, contribuição que este estudo pretende oferecer a partir dos recursos metodológicos e conceituais da memória social.

\section{Memória Social e Comunidades Tradicionais}

A importância da abordagem da memória social nas diversas formas de organização social dos grupos humanos, especialmente em comunidades com tradição oral de transmissão de conhecimento, como é o caso de muitos grupos ciganos, cria a possibilidade de registro da história viva do grupo e auxilia na investigação dos elementos simbolicamente significativos, aqueles centrais à elaboração de sua identidade social (Cabecinhas, 2006; Connerton, 1999).

De acordo com Jedlowski (2005) e Sá (2005), a memória, na esfera psicossocial, pode ser entendida como processo social, interdependente às pertenças sociais dos indivíduos e ao sistema de crenças e valores dos grupos e sociedades, que reconstroem incessantemente o conteúdo vivenciado em 
função das necessidades e demandas da realidade presente. A memória social seria, portanto, a reconstrução do passado em função do presente. Nessa máquina do tempo, que opera cotidianamente em nossas vidas, o conteúdo rememorado nunca é o mesmo, ou seja, as experiências do passado sofrem constantemente uma reelaboração, posto que também os indivíduos, seus contextos socioculturais de inserção e seus quadros de referência (para o modo como vivem e interpretam o mundo) estão em transformação (Jovchelovitch, 2008).

$\mathrm{Na}$ Psicologia Social, os estudos em memória social têm assumido como ponto de partida, principalmente, as ideias originalmente propostas pelo sociólogo francês Halbwachs (1877-1945) e pelo psicólogo inglês Bartlett (1886-1969), defendendo-se a concepção da memória social como construção, que se desenvolve por meio de uma combinação daquilo que foi experienciado com elementos da sociedade e da cultura (Frochtengarten, 2005; Nascimento \& Menandro, 2005; Sá, 2005; Valentim, Trindade \& Menandro, 2010).

Seguidor das ideias de Durkheim, Halbwachs (2006) postulou que a memória individual poderia ser reduzida e compreendida pela memória coletiva. Segundo ele, a memória é social porque (i) recordamos um mundo composto por pessoas e grupos sociais (ou seja, é social porque o conteúdo é social); (ii) está fundamentada nos quadros sociais de referência (rituais, cerimonias e eventos diversos que marcam a nossa cultura, em consonância com as ideologias dominantes); e (iii) alicerça-se na linguagem e na comunicação interna e externa aos grupos, processo marcadamente social. De acordo com Cabecinhas (2006), a questão básica desse autor seria o papel do indivíduo e da sociedade na construção e transmissão das memórias.

A Bartlett, por sua vez, é atribuída a contribuição de ter introduzido a noção de convencionalização social, que trata da adaptação do conteúdo recordado (um texto, uma imagem, um acontecimento, uma ideia) às convenções do grupo (usos, costumes, valores, estereótipos) quando este é repassado de um grupo a outro. Em outras palavras, a memória como processo também sobre influência do sistema normativo instituído entre os grupos humanos; memória que, segundo Bartlett, codifica percepções e que é a expressão individual do pertencimento a uma cultura ou a um grupo social, constituída e consolidada nas redes de relacionamentos sociais Jedlowski, 2001).

Considerando as proposições de Halbwachs e de Bartlett, Sá (2005, 2007) identifica cinco princípios unificadores desse campo de estudo - perspectivas sociológica e psicológica que se integram pela compreensão da memória não como uma reprodução do passado, mas como construção no interior da dinâmica sociocultural da realidade presente. Seguindo essa perspectiva, podemos assumir o processo do recordar como: (i) construtivo, posto que as imagens do passado são modificadas ao longo de sua transmissão por meio da linguagem (que fornece as categorias por meio das quais apreendemos a realidade), bem como reconstruídas em função do sistema normativo e ideológico vigentes; (ii) pessoal, pois os 
indivíduos participam ativamente na rememoração. $\mathrm{Na}$ perspectiva social da memória, não são consideradas as abordagens que tomam a memória como exclusivas da produção das sociedades e grupos sociais (visão sociologizante); (iii) mesmo sendo pessoais, dependem da interação e comunicação sociais; (iv) indissociável do pensamento social, uma vez que o que se lembra do passado está conectado ao que se sabe sobre ele; e (v) mobilizado pela motivação e pela dimensão afetiva, como dimensões construtivas da memória (Sá, 2005).

No presente trabalho, focalizam-se as memórias práticas (Sá, 2005, 2012), que são aquelas encontradas nas ações e nos modos de fazer das pessoas e das comunidades, como vivência prática da cultura em diferentes esferas da vida social, como os costumes e as tradições (Cabecinhas, 2006), bem como cerimônias comemorativas (Connerton, 1999). De acordo com Sá (2007, p. 294), as memórias práticas se associam ao "estofo discursivo, imagético e principalmente afetivo das demais instâncias", sendo transmitidas por meio dos diferentes mecanismos de socialização, com natureza social mais conservadora do que voltada para os processos de mudança social. No caso de grupos como os ciganos calon, essa transmissão e esforço de manutenção da cultura tem se dado, principalmente, pela oralidade.

Como mecanismo essencial do fazer histórico em grupos e comunidades, a tradição oral configura-se como forma de transmissão do conjunto de conhecimento que organiza o modo de vida dos indivíduos e orienta as práticas cotidianas, no próprio grupo e nas relações com o contexto de interação fora da comunidade. Entendemos que os elementos simbolicamente significativos ao grupo, retratados nas narrativas, são centrais ao processo de representação endogrupal e à elaboração e transmissão dos elementos identitários aos seus membros, às novas gerações (Pollak, 1989, 1992). De acordo com Bossi (2003), o conjunto de lembranças é uma construção social do grupo em que a pessoa vive, e onde coexistem elementos da seleção e rejeição daquilo que será lembrado. Para os grupos de etnia cigana, a relação com o passado do grupo assume profunda importância para a manutenção da tradição e identidade grupal (Blasco, 2001; Stoyanova, Doseva, Gergov \& Virginás-Tar, 2015).

Tendo em vista os apontamentos apresentados, ainda que a produção internacional saliente tais aspectos, há poucos achados na produção nacional que ampliem a compreensão das dinâmicas psicossociais do grupo diante da realidade brasileira. Desse modo, espera-se que os resultados gerados possam contribuir para ampliar o corpo de conhecimento produzido acerca da cultura cigana e fomentar o desenvolvimento de políticas públicas focalizando as demandas dessa população, bem como auxiliar na desmitificação dos estereótipos negativos, largamente difundidos no pensamento social hegemônico, núcleo de preconceito, de estigmatização e de discriminação social contra os membros desse grupo. Espera-se, ainda, contribuir com o processo do fazer memória entre as comunidades ciganas e auxiliar na manutenção e socialização da memória das 
comunidades ciganas a partir de suas próprias narrativas.

\section{Método}

Tendo em vista o objetivo de conhecer e analisar as memórias práticas entre membros de uma comunidade cigana do estado do Espírito Santo, a partir de narrativas do grupo sobre o seu passado, e orientados por estratégias metodológicas que valorizam a memória como processo dinâmico e em constante construção (Nascimento \& Menandro, 2005; Sá, 2005), o estudo foi desenvolvido com base na perspectiva etnográfica conjugada com entrevistas em profundidade, que visam obter a descrição e a compreensão de fenômenos socioculturais presentes na vida da comunidade cigana, a partir do campo de significação das pessoas que vivenciam cotidianamente a realidade desse grupo étnico (Souza, 2015).

Informamos ainda que a pesquisa foi devidamente aprovada pelo Comitê de Ética em Pesquisa com Seres Humanos, com registro número CAAE 76459417.8.0000.5542.

\section{Participantes e Procedimentos de Coleta dos Dados}

A partir da perspectiva etnográfica, foram realizadas visitas quinzenais ao acampamento cigano durante o período de outubro de 2016 a maio de 2017 (oito meses), quando o registro dos eventos cotidianos era anotado em diários de campo. Em um segundo momento de coleta dos dados (em outubro de 2017), foram realizadas entrevistas individuais e em profundidade com 10 integrantes do grupo cigano calon (cinco homens e cinco mulheres), com idades acima de 50 anos. Os critérios de seleção dos participantes para as entrevistas foram: integrar as primeiras gerações do grupo, ter vivenciado períodos de nomadismo e de seminomadismo com a comunidade e estar residindo no acampamento no período de coleta dos dados.

\section{Instrumentos e Tratamento dos Dados}

Foram utilizados como instrumentos para coleta dos dados os recursos de diário de campo e de roteiro semiestruturado para entrevistas, esse último contendo questões relacionadas às seguintes unidades temáticas: a) identificação dos participantes (nome, idade e contexto familiar); b) nomadismo e domínio territorial, com questões referentes às memórias do modo de vida nômade e às práticas realizadas naquele período; c) práticas e tradições, com questões abordando as práticas cotidianas, os acordos matrimoniais e as tradições relacionadas ao casamento cigano, às festas e às músicas; d) linhas do desenvolvimento humano e constituição da rede familiar, com questões acerca das memórias em cada fase do desenvolvimento (criança - adulto - velhice) e da formação familiar e grupal; e) memórias e ensinamentos dos antepassados (gerações já falecidas), com questões sobre os ensinamentos recebidos por meio da oralidade, as práticas desses ensinamentos para as gerações mais novas e os conteúdos transmitidos para os filhos e os netos; e f) memórias práticas de vivência da ciganidade. 
As informações registradas nos diários de campo foram organizadas e sintetizadas a fim de proporcionar a contextualização do grupo e do território do acampamento. As narrativas dos participantes, obtidas por meio das entrevistas, por sua vez, foram analisadas utilizando a classificação hierárquica descendente (CHD), para tal foi usado o software Alceste - Analyse Lexicale par Contexte d'un Ensemble de Segments de Texte (Reinert, 1990).

A CHD é uma análise lexicográfica de materiais textuais que permite segmentar $\mathrm{e}$ estabelecer similaridades entre os segmentos e hierarquias de classes de palavras, de modo a classificar os segmentos de texto em função dos seus respectivos vocabulários (Camargo, 2005). Nascimento e Menandro (2006) sugerem o uso dessa análise em estudos exploratórios, como no caso do presente estudo, tendo em vista a possibilidade de se obter um mapeamento introdutório e abrangente do corpus textual a partir de agrupamentos lexicais, bem como a possibilidade de se observar as relações e oposições desses agrupamentos.

\section{Resultados}

Os resultados encontrados foram sistematizados em duas seções principais: a) contextualização do grupo, a partir de dados gerais sobre a comunidade; e b) no tempo dos ciganos: práticas e rememorações das primeiras geracõos do grupo, conteúdo que reúne a análise gerada pela CHD, com a apresentação de UCEs características a fim de contextualizar o universo de emergência dos significados constitutivos de cada classe.

\section{Contextualização do Grupo}

O grupo cigano acompanhado no presente estudo é da etnia calon, que há mais de 40 anos está presente em território capixaba. No período da coleta dos dados, o acampamento estava localizado em uma área urbana de um município no estado do Espírito Santo, e era formado por cerca de 20 barracas/famílias.

A imagem apresentada na Figura 1 se refere à configuração espacial no interior de uma barraca cigana. Apesar de serem diferentes em relação ao tamanho, estrutura e recursos (eletrodomésticos, móveis, decoração, entre outros), que variam de acordo com as condições financeiras da família, podemos observar um padrão de organização das barracas presentes no território no período de coleta dos dados, quando o estudo foi realizado. 
Figura 1. Desenho retratando o interior de uma barraca cigana

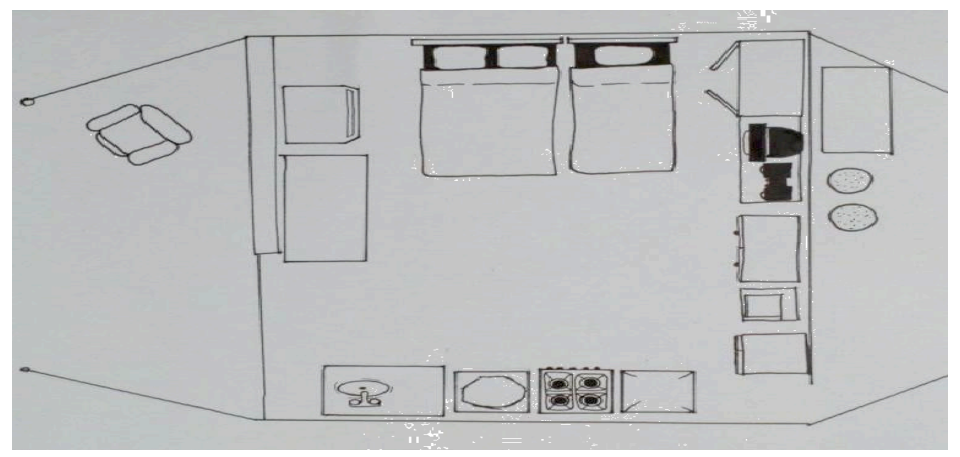

Fonte: Elaborada pelas autoras.

Devido à dinâmica do grupo e sua organização baseada em relações de parentescos e de afinidades entre as famílias, frequentemente, havia algumas famílias chegando e/ou se mudando para outros bairros e cidades da região, mas, pelo menos, 50 pessoas (incluindo idosos, adultos e crianças) se mantinham no mesmo acampamento. A tarefa de sistematizar a organização entre as famílias, inclusive de localização espacial das barracas no acampamento (Figura 2), bem como proceder ao contato e mediação com os não ciganos, era de domínio do líder-cigano.

Figura 2. Desenho retratando o acampamento cigano onde o estudo foi desenvolvido

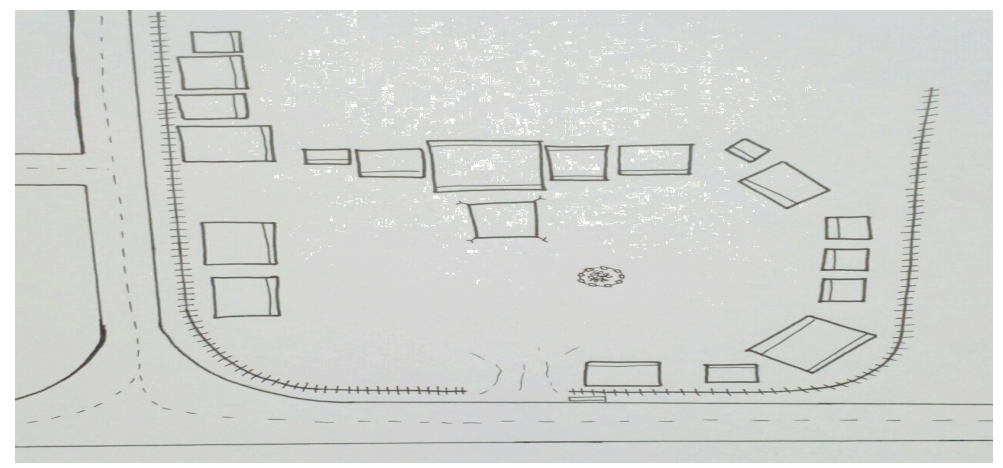

Fonte: Elaborada pelas autoras.

Os ciclos de formação geracional se orientam pelo nascimento de unidades familiares. Logo, o casamento marca a passagem para a vida adulta e, como os jovens se casam cedo, as gerações se renovam de forma rápida. Algumas crianças são prometidas em acordos matrimoniais pelos pais, e esses laços são cultivados ao longo dos anos entre as famílias envolvidas até o momento de oficializar o matrimônio. Ao se casarem, os jovens passam a viver em sua própria barraca e a ter as mesmas 
responsabilidades dos adultos, como o trabalho, o cuidado com a barraca, o provimento da família, entre outras tarefas.

Os idosos do grupo relatam períodos de uma diáspora pela região na qual viviam de forma nômade, realizando viagens em um tempo denominado por eles como "o tempo das tropas de mula". Nesse período, eles mantinham o estilo de vida entre as viagens, levando consigo suas barracas, seus animais e todos os seus pertences, e andavam por longos períodos, enfrentando todas as adversidades climáticas até encontrarem um lugar para montar o acampamento. Contudo, com o passar dos anos e pressionados pela urbanização dos espaços, o grupo foi se fixando em diversas regiões capixabas, passando a realizar apenas pequenas migrações locais nos limites do próprio território urbano e entre cidades próximas.

\section{No Tempo dos Ciganos: Práticas e Rememorações das Primeiras Gerações do Grupo}

Com aproveitamento de $80 \%$ do material analisado (Figura 3), o tratamento dos dados referentes às narrativas das primeiras gerações da comunidade foi Figura 3. Dendrograma de classes estáveis realizado utilizando o Programa Alceste e gerou um conjunto de seis classes organizadas em dois eixos principais ("Ciganidade resistente" e "Transformações em curso", com força de ligação de 0,1), subdividindo-se o primeiro eixo em dois subeixos principais ("Práticas cotidianas e relações de gênero" e "Tradições e costumes ciganos", com força de ligação de 0,39 e 0,66 , respectivamente).

O eixo 1, chamado de ciganidade resistente, é composto pelos subeixos "práticas cotidianas e relações de gênero" e "tradições e costumes ciganos" (ver Figura 3). Os temas centrais apresentados nesse eixo são as normas, divisões de tarefas, festas e celebrações, tendas ciganas e nomadismos, bem como a terra prometida (expectativa de conquista de território onde as famílias ciganas pudessem se fixar). Apresenta-se nesse eixo também o conteúdo que reflete a resistência do viver a ciganidade nos tempos e modos de vida diferenciados, apesar da discriminação sofrida no contato com o universo não cigano. 


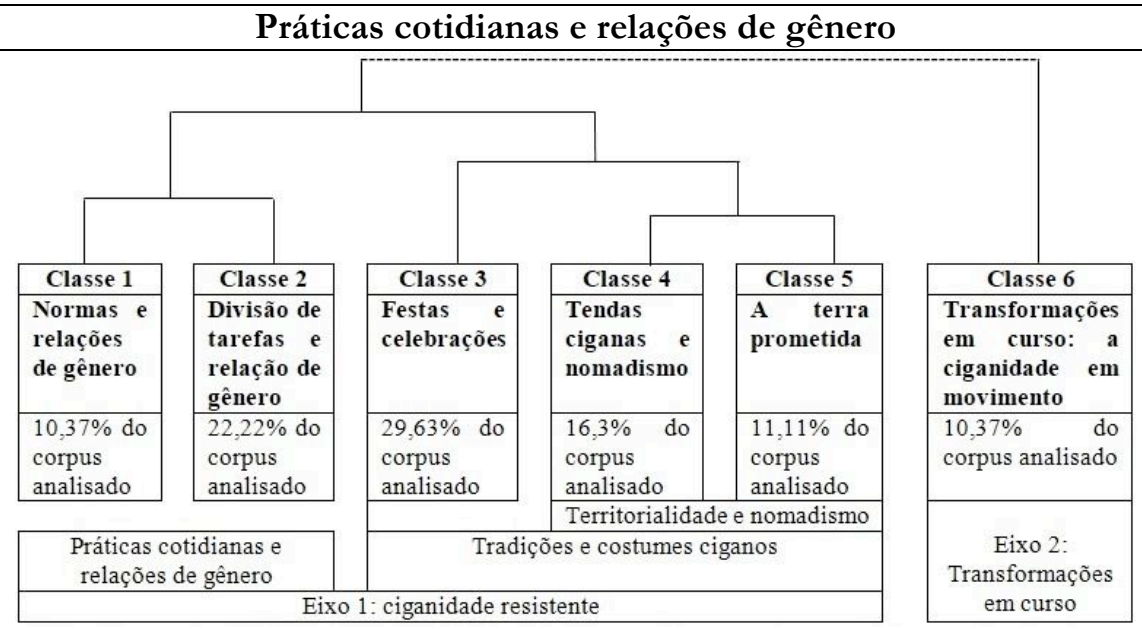

Nota: Para maior detalhamento dos eixos, subeixos e classes, optou-se pela apresentação dos termos característicos em tabelas específicas, conforme Tabela

1 (subeixo "práticas cotidianas e relações de gênero"), Tabela 2 (subeixo

"tradições e costumes ciganos") e Tabela 3 (eixo "transformações em curso").

Fonte: Elaborada pelas autoras.

O subeixo "práticas cotidianas e relações de gênero" é composto pelas classes $1 \mathrm{e}$ 2 (ver Tabela 1), que reúnem conteúdos a respeito das relações de gênero que são estabelecidas na comunidade e das diferenças que acarretam no dia a dia das pessoas, visto que o gênero está diretamente relacionado com as vestimentas, normas de interação, trabalhos e obrigações na comunidade.

A classe 1 (Normas e relações de gênero) parece referir-se às atribuições para homens e mulheres, marcadas por diferenças, e aos espaços identitários da linha da vida (como o ser criança e velho). Elementos como certo, regra e pode revelam o caráter normativo dessa classe em relação ao ordenamento da vida cigana, com especificidades de gênero em que "a mulher lava roupa, faz a comida, lê mão, mexe com tudo aí; e o homem barganha carro, compra carro e troca" (UCE: x2 40; Mulher cigana). Além da escola como espaço de aprendizado, a função de transmissão oral da ciganidade pelos "troncos velhos”" é ressaltada: “já nasce de tudo. Quando faz 1, 2, 3 anos, eles aprende a conversar tudo com os velho. É igual um filhotinho de passarinho, quando ele sai da casca, já sai esperto" (UCE: x2 13; Homem cigano).

6 A expressão "troncos velhos" é utilizada pelos próprios ciganos para se referir às gerações mais antigas do grupo. 


\begin{tabular}{|c|c|c|c|c|c|c|c|}
\hline \multicolumn{4}{|c|}{$\begin{array}{c}\text { Classe } 1 \\
\text { Normas e relações de gênero }\end{array}$} & \multicolumn{4}{|c|}{$\begin{array}{c}\text { Classe } 2 \\
\text { Divisão de tarefas e relação de gênero }\end{array}$} \\
\hline \multicolumn{4}{|c|}{$10,37 \%$ do corpus analisado } & \multicolumn{4}{|c|}{$22,22 \%$ do corpus analisado } \\
\hline Termo & Chi2 & Termo & Chi2 & Termo & Chi2 & Termo & Chi2 \\
\hline Ali & 3,56 & Homem & 54,27 & Acabou & 3,51 & Hoje & 3,80 \\
\hline Certo & 4,48 & Lê mão & 2,63 & Acordo & 14,43 & Lenha & 10,74 \\
\hline Cigana & 14,37 & Mesma & 6,96 & Agora & 15,89 & Mãe & 20,97 \\
\hline Coisa & 11,78 & Mim & 4,90 & Ainda & 4,29 & Mais & 3,58 \\
\hline Comida & 26,52 & Mulher & 19,82 & Algum & 3,51 & Manhã & 14,43 \\
\hline Criança & 13,76 & Nasce & 13,56 & Amor & 3,51 & Meu & 4,29 \\
\hline Diferença & 12,05 & Pode & 3,03 & Andava & 6,64 & Minha & 15,05 \\
\hline Diferente & 4,90 & Regra & 10,46 & Antigamente & 10,64 & Muito & 6,39 \\
\hline Ensina & 13,76 & Roupa & 3,56 & Cuidado & 6,64 & Mulher & 2,19 \\
\hline Entrar & 17,38 & Tem & 5,23 & Dia & 8,09 & Nada & 10,03 \\
\hline Escola & 6,96 & Velho & 10,46 & Dizer & 3,51 & Noite & 13,57 \\
\hline Exemplo & 6,96 & Vida & 5,47 & Dormir & 14,43 & Onde & 6,64 \\
\hline- & - & - & - & Ela & 7,25 & Pai & 6,64 \\
\hline - & - & - & - & Entende & 3,09 & Pequeno & 14,43 \\
\hline - & - & - & - & $\mathrm{Eu}$ & 4,40 & Tarde & 10,74 \\
\hline - & - & - & - & Faz & 2,41 & Velha & 7,98 \\
\hline - & - & - & - & Grupo & 3,09 & Viajava & 10,74 \\
\hline
\end{tabular}

Fonte: Elaborada pelas autoras.

Especificando a divisão de tarefas já mencionada na classe 1 , a segunda classe trata de práticas e acontecimentos cotidianos da vida cigana (Ver Tabela 1), envolvendo a rememoração (antigamente, hoje) tanto do passado quanto da vivência atual da rotina do grupo pelo indivíduo (eu, meu, minha), especialmente, sobre o tempo de nomadismo: "Eu sou de lá do norte. Andava muito de cavalo, agora não tem cavalo mais. Trocar, vender, barganhar... Nossa senhora, nem é bom falar, era muito difícil, tem dia que a gente viajava de manhã até a noite, saía sem almoço" (UCE: x2 14; Homem cigano).

A jornada do dia (manbã, tarde e noite) e sua rotina (acordo, faz coisas, faz nada, vai dormir) pelos troncos velhos referem-se a um conjunto de atividades mais centradas na vida doméstica: "cato lenha, chego depois de catar lenha e vou tratar do porco, das galinhas e pronto. Cata lenha aqui no lixão daqui; no outro lixão da frente de lá e, de noite, eu vou dormir, caçar minha cama" (UCE: x2 22; Mulher cigana). Ainda nessa classe, são relatados costumes da comunidade cigana envolvendo a quiromancia, prática associada às mulheres mais velhas do grupo - "as velha das antiga, se ela pegasse a palma da sua mão pra olhar sua sorte, você podia saber que era verdade" (UCE: x2 20; Mulher cigana).

Conforme dados apresentados na Tabela 2, o subeixo "tradições e costumes ciganos" é formado pelas classes 3, 4 e 5 e trata sobre práticas e costumes vividos pela comunidade cigana. Em linhas gerais, a classe 3 ressalta as comemorações e eventos que acontecem na comunidade (promessa, casamento, batizado, festas dos santos), bem como das relações que os sujeitos do grupo estabelecem entre si (relação, chama ciganos, reunião) e da organização para a vivência desses eventos. $O$ fragmento apresentado a seguir ilustra o conteúdo central dessa classe: "Eles vêm aqui, fazer festa, tudo 
amigo; Nós vamos na festa deles e eles vêm aqui. Quando tem festa, eles vem tudo. Final de ano, às vezes, tem um casamento, aniversário... geralmente, quando tem festa, o pessoal da rua tudo vem" (UCE: x2 17; Homem cigano).

Tabela 2. Elementos que compõem o subeixo tradições e costumes ciganos

\begin{tabular}{|c|c|c|c|c|c|c|c|c|c|c|c|}
\hline \multicolumn{12}{|c|}{ Tradições e costumes ciganos } \\
\hline \multirow{2}{*}{\multicolumn{4}{|c|}{$\begin{array}{c}\text { Classe } 3 \\
\text { Festas e celebrações } \\
\end{array}$}} & \multirow{2}{*}{\multicolumn{4}{|c|}{$\begin{array}{c}\text { Classe } 4 \\
\text { Tendas ciganas e nomadismo }\end{array}$}} & \multirow{2}{*}{\multicolumn{4}{|c|}{$\begin{array}{c}\text { Classe } 5 \\
\text { A terra prometida }\end{array}$}} \\
\hline & & & & & & & & & & & \\
\hline \multicolumn{4}{|c|}{$29,63 \%$ do corpus analisado } & \multicolumn{4}{|c|}{$16,3 \%$ do corpus analisado } & \multicolumn{4}{|c|}{$11,11 \%$ do corpus analisado } \\
\hline Termo & Chi2 & Termo & Chi2 & Termo & Chi2 & Termo & Chi2 & Termo & Chi2 & Termo & Chi2 \\
\hline Aniversário & 7,29 & Manda & 4,07 & Acha & 21,24 & Mesmo & 3,79 & Acha & 7,45 & $\mathrm{Ia}$ & 9,59 \\
\hline Aquele & 2,02 & Mundo & 2,33 & Acostumada & 3,43 & Moram & 21,17 & Água & 6,31 & Jeito & 4,39 \\
\hline Bastante & 2,02 & Naquele & 4,07 & Barraca & 19,60 & Morar & 5,71 & Alguma & 5,63 & Lugar & 12,45 \\
\hline Batizado & 9,79 & Nossa & 2,62 & Casa & 29,55 & Olha & 7,27 & Barraca & 4,22 & Mesma & 6,31 \\
\hline Casamento & 2,90 & Nosso & 2,30 & Cigano & 6,73 & Parado & 3,43 & Bem & 2,28 & Mudar & 17,04 \\
\hline Chama & 4,07 & Organização & 2,02 & Construir & 3,43 & Passado & 3,43 & Carro & 6,31 & Muita & 10,85 \\
\hline Chega & 6,32 & Outro & 5,86 & Deu & 3,82 & Porque & 9,67 & Coisa & 10,38 & Pessoa & 3,17 \\
\hline Cigano & 2,10 & Pessoal & 2,02 & Diferença & 2,05 & Roupa & 11,68 & Construir & 6,31 & Sair & 6,31 \\
\hline Conta & 8,69 & Pode & 2,62 & Diferente & 2,14 & Sempre & 5,71 & Deixa & 6,00 & Ser & 12,80 \\
\hline Dele & 2,02 & Promessa & 7,29 & Fala & 3,43 & Ser & 2,98 & Depois & 6,00 & Ter & 33,45 \\
\hline Ele & 6,87 & Quiser & 7,29 & Ficar & 2,80 & Tipo & 5,71 & Ficar & 6,00 & Vai & 12,29 \\
\hline Espaço & 2,02 & Relação & 2,33 & Gosto & 3,43 & Tradição & 11,68 & For & 9,59 & Vila & 37,92 \\
\hline Falou & 4,07 & Reunião & 7,29 & Jeito & 2,14 & Ventania & 5,71 & - & - & - & - \\
\hline Fazer & 14,09 & Rua & 7,29 & Melhor & 7,08 & Sei & 2,14 & - & - & - & - \\
\hline Festa & 2,84 & Santo & 2,30 & - & - & - & - & - & - & - & - \\
\hline Foi & 4,43 & Tudo & 2,45 & - & - & - & - & - & - & - & - \\
\hline Gente & 3,43 & Vem & 5,79 & - & - & - & - & - & - & - & - \\
\hline Língua & 2,33 & Você & 4,13 & - & - & - & - & - & - & - & - \\
\hline
\end{tabular}

Fonte: Elaborada pelas autoras.

A classe 4 (Ver Tabela 2), por sua vez, parece retratar a moradia dos ciganos e as tradições que envolvem essa dimensão: "Não gosto de morar em casa, não. Ficar assim, dentro da casa, pra mim, nossa! A pessoa está acostumada a ficar na barraca. Cigano vive em barraca!" (UCE: x2 21; Mulher cigana). Mesmo com algumas dificuldades envolvendo a moradia em barraca, defendem essa preferência: "Já aconteceu de cair... aquela vez que deu a chuva forte, esses dias mesmo deu uma ventania, foi tudo pro chão” (Mulher cigana); "é tradição do cigano morar em barraca" (UCE: x2 13; Homem cigano).

Assim como defendem a barraca como elemento central da cultura cigana, também a roupa típica é destacada como vivência da ciganidade: "Ah, porque quando acaba a tradição da barraca, não usa mais roupa cigana, não continua mais na tradição" (UCE: x2 12; Mulher cigana). Dessa forma, as primeiras gerações descrevem o cigano e a cigana verdadeiros como: "A gente olha muito pelo chapéu, cinto, pela botina. Os homens pelo 
chapéu e as mulheres pelo vestido" (UCE: x2 16; Homem cigano). Essa classe também mostra a questão do movimento que os ciganos faziam antigamente em contraponto com o que ocorre atualmente em alguns grupos, com práticas de seminomadismo ou de fixação territorial (diferença, passado, tradição, melhor): “A gente não é acostumado a morar em casa. É tradição de cigano a barraca... mas andando, a gente cansa muito. Se a gente fica parado, a gente ganha mais força" (UCE: x2 10; Homem cigano).

A classe 5, denominada de "A terra prometida", faz referência ao sonho dos ciganos de conquistarem um espaço para construção de uma vila cigana. Descrevem como seria esse espaço e defendem a importância de um acampamento permanente para as famílias ciganas: "A vila cigana tem que ter energia, banheiro, água, escola" (UCE: x2 26; Homem cigano). Os relatos ainda destacam otimismo em relação à efetivação do projeto da vila cigana, a animação em relação à disposição do espaço, assim como a expectativa de manutenção das barracas. Fala-se também da expectativa positiva de unir os ciganos em uma comunidade ampla: "Nós precisa de um lugar para nós ficar, nós precisa de uma comunidade para nós ficar quieto" (UCE: x2 08; Homem cigano).

Por outro lado, o eixo 2 (Ver Figura 3), denominado de "transformações em curso", é composto exclusivamente pela classe 6 , que reúne elementos que sugerem a descrição de mudanças sentidas no grupo, de acordo com o tempo e o local em que se encontram.

Tabela 3. Elementos que compõem o eixo transformações em curso

\begin{tabular}{|c|c|c|c|}
\hline \multicolumn{4}{|c|}{$\begin{array}{l}\text { Classe } 6 \\
\end{array}$} \\
\hline \multicolumn{4}{|c|}{$10,73 \%$ do corpus analisado } \\
\hline Termo & Chi 2 & Termo & Chi 2 \\
\hline Acampamento & 10,46 & Meses & 21,41 \\
\hline Ano & 22,25 & Mesmo & 6,05 \\
\hline Antes & 18,52 & Nasceu & 13,76 \\
\hline Aqui & 10,12 & Nasce & 10,61 \\
\hline Barraca & 2,41 & Parado & 6,96 \\
\hline Essa & 5,47 & Pouco & 3,56 \\
\hline Esta & 10,61 & Quanto & 63,81 \\
\hline Grupo & 9,57 & Vida & 5,47 \\
\hline já & 8,51 & Tempo & 35,96 \\
\hline
\end{tabular}

Fonte: Elaborada pelas autoras. 
Nessa classe (Tabela 3), são relatados aspectos relacionados ao tempo de permanência (tempo, acampamento, aqui, anos, meses), bem como relativos à relação da comunidade com $\mathrm{O}$ território e grupo (grupo, vida, parado, nasceu, nasce). Portanto, são aspectos que dizem também de uma relação de fixação local que se diferencia do nomadismo (antes vivenciada por eles). Mencionam, ainda, a dificuldade de encontrar um lugar para sustentar o nomadismo, condição que revela o contexto de exclusão e de marginalidade social em que muitos grupos ciganos se encontram na atualidade: "Ah, porque nós vai caçar outro local, pra gente levantar barraca, outro local, a gente não acha" (UCE: x2 18; Mulher cigana).

\section{Discussão}

Com o objetivo de conhecer e analisar as memórias práticas entre as primeiras gerações de ciganos de um acampamento localizado em área urbana no estado do Espírito Santo, os principais resultados encontrados evidenciam a centralidade das relações de gênero, do sistema normativo e do referencial territorialidade/nomadismo, bem como das celebrações (que marcam os ciclos da vida) e dos festejos (fortalecendo os laços entre diferentes grupos ciganos da região).

Como categoria social ordenadora dos espaços sociais no grupo, as relações de gênero podem ser observadas nas expressões das normas grupais e nas práticas sociais cotidianas que conferem espaços diferenciados a homens e mulheres ao longo do ciclo de vida dos membros do grupo (classes 1 e 2 - Figura 3). De fato, de acordo com Pizzinato (2009), os papéis de gênero nesse contexto precisam ser pensados integrando elementos da etnia, de etapas do desenvolvimento humano, bem como da tradição e da pertença social. Como já observado por outros autores, às mulheres reserva-se o domínio do espaço do lar, com o cuidado com a barraca, filhos e marido, além da quiromancia, que seria uma prática específica do universo feminino. Aos homens, por sua vez, compreende o provimento da família, principalmente, por meio do sistema de 'barganhas', que são estabelecidas tanto entre ciganos quanto entre ciganos e não ciganos (Ceneda, 2002; Fonseca, 1996; Jovanovi , Kóczé \& Balogh, 2015; Mendes, 2015).

Se as barracas (e sua diferenciação com os povos que vivem em casas, os não ciganos) e as vestimentas típicas apresentam-se como expressão do ser cigano (tanto na própria comunidade quanto entre não ciganos), posto que reforçam o reconhecimento e vivência prática dessa identidade no cotidiano (Sá, 2005), o nomadismo, na atualidade, tem sido ponto de debate (classes 4, 5 e 6). Apesar do estilo de vida nômade ser uma das características comumente atribuídas aos grupos ciganos (Batista \& Medeiros, 2015), também aponta para uma estratégia historicamente adotada como forma de preservação em meio às perseguições e aos banimentos que diversos grupos ciganos sofreram em diferentes espaços de contato com não ciganos (Batista \& Medeiros, 2015; Kende et al., 2017; Moonen, 2011). O nomadismo, portanto, tem se tornado uma questão dilemática entre alguns grupos, que, apesar de se manter ligado a um tempo bom e de liberdade e que 
constitui uma memória prática referenciada em centenas de anos da história desse povo, também se associa a elementos de exclusão presentes na memória das primeiras gerações (Brasil, 2013).

A ideia de uma territorialidade que reúna os diversos grupos ciganos da região ("A terra prometida") se apresenta, dessa forma, como possibilidade de acesso a recursos como escola para as crianças e hospital/unidade de saúde para toda a comunidade, mantendo-se, contudo, a possibilidade de mobilidade local ou viagens temporárias entre diferentes acampamentos, estratégia que reuniria o melhor da fixação territorial e do nomadismo. Conforme aponta Vaz (2009), para os ciganos, o território funciona como um instrumento de fixação, que permite um local compartilhado para reprodução cultural das famílias ciganas, tornando-se sinônimo de segurança e de "uma vida melhor", cheia de perspectivas e representações do mundo vivido.

Materializando-se como processo da memória social, as práticas cotidianas são rememoradas, compartilhadas e reafirmadas também por meio das comemorações, que celebram as tradições do grupo (Valentim et al., 2010) e coroam a vivência da ciganidade (classe 3). Batizados, promessas entre famílias, casamentos e festas de santos estão entre os eventos mais festejados, integrando as famílias ciganas do acampamento e diferentes grupos ciganos da região, além de tornar ainda mais positiva a identidade cigana para os membros dos grupos. De fato, de acordo com Connerton (1999), rituais comemorativos têm grande poder de significação, conferindo valor e sentido à vida das pessoas e agindo como conexão entre diferentes temporalidades.

Em um grupo com língua ágrafa e tradição oral de transmissão de conhecimento, a função das gerações mediadoras do tempo dos ciganos ou de construção desse passado social do grupo, os chamados troncos velhos, torna-se essencial para a elaboração de memórias comuns (Sá, 2007). Os idosos tomam a palavra como testemunhas vivas do passado (Bosi, 2003) e tornam-se responsáveis pela manutenção da memória do grupo e de suas tradições, processo elementar para a construção de sua identidade social. De acordo com Pollak (1992, p. 204), a memória pode ser compreendida como dimensão da identidade, "na medida em que ela é também um fator extremamente importante do sentimento de continuidade e de coerência de uma pessoa ou de um grupo". Dessa forma, cada ciclo geracional fornece às novas gerações os recursos de referência para a materialização da memória prática e de vivência e manutenção da ciganidade (Fonseca, 1996; Ravnbøl, 2010).

Também Cabecinhas (2006) integra o debate entre memória e identidade sinalizando a sua importância para o futuro, a fim de orientar relações dentro e fora do grupo, bem como incidindo sobre processos de mudança, adaptação ou resistência, como verificado no estudo. Para os grupos de etnia cigana, a memória seria mais do que um conjunto de recordações, posto que envolve um processo ativo de (re)construção permanente trabalhando em favor da manutenção da referência étnica grupal. Os passados (alguns mais e outros menos) são mantidos à tona, "à flor da pele" (Sá, 2012), de modo que as lembranças 
compartilhadas pelos indivíduos permitem criar uma noção de continuidade do grupo (suas origens e passado comum). Stoyanova et al. (2015), em um estudo acerca das diferenças interculturais em relação ao sentimentalismo e à nostalgia de grupos étnicos minoritários, revelam que o passado não é igualmente importante para as diferentes minorias étnicas, pois estas selecionam diferentes estratégias adaptativas na sociedade.

Esquecer e lembrar são, portanto, dimensões que organizam os modos de vida dos grupos e comunidades e o cotidiano das pessoas, tarefa que compreende o passado rememorado ou reconstruído no interior das relações e interesses do presente, bem como o empenho de construir o futuro trabalhando com novas gerações, os marcadores identitários no jogo e tensão da vida social (Nascimento \& Menandro, 2005).

Das modulações individuais à formação do próprio pensamento social e à dinâmica de nossa cultura, na memória social, como processo, revela-se um campo em disputa, em que também atua o controle social pelo exercício do poder (Cabecinhas, 2006). O que é lembrado, como é lembrado, assim como os eventos que são esquecidos ou esmaecidos, podem ser orientados pela defesa de um campo de significação a serviço dos grupos e indivíduos. A memória é, portanto, um processo identitário (Pollak, 1989, 1992). Como tal, é também um mecanismo que revela as relações de poder no contexto das hierarquias grupais, especialmente, entre aqueles que são usados para pressionar a construção de uma única história, reforçando estereótipos que fundamentam preconceitos e discriminação social contra determinados segmentos, como no caso dos ciganos (Bonomo et al., 2012; Carvalho et al., 2012). No entanto, a memória social também pode ser instrumento de contestação, ressignificação e retomada da esfera pública.

Ao socializar as suas memórias, os diferentes grupos passam a existir no registro social, o que indica a possibilidade de tornar esse espaço mais democrático (Bossi, 2003). Entender, portanto, os fenômenos que se produzem no terreno dessa cotidianidade esfera das contradições, força motriz das diferentes sociabilidades e daquilo que um dia chamaremos história (Jovchelovitch, 2008) -, alinha-se a essa tarefa de se promover construções sociais que contribuam para as pautas das minorias sociais.

\section{Considerações Finais}

O estudo teve como objetivo analisar as memórias práticas entre membros das primeiras gerações de um grupo cigano de área urbana no estado do Espírito Santo. Para além das possíveis contribuições dos resultados encontrados, o desenvolvimento de um estudo para fins de registro de eventos e temáticas salientes ao grupo a partir dos próprios ciganos, especialmente envolvendo o segmento de idosos (ainda pouco abordados em estudos sobre os ciganos), pode ser ressaltado como um dos pontos positivos deste trabalho, ao contribuir para o processo de construção de uma historiografia cigana.

Sobre a eventual leitura e interpretação dos resultados, orientada por uma perspectiva 
generalizante, parece ser relevante ressaltar a especificidade do contexto e da vivência dos núcleos familiares que compõem o grupo em questão, não se pretendendo assumir as memórias sociais analisadas como dado geral dos ciganos em território capixaba, tampouco dos ciganos calon, em específico.

Entre as limitações identificadas no desenvolvimento do estudo, observa-se a necessidade de maior investimento em estratégias de coleta de dados a partir de recursos que envolvem métodos de observação, para maior aprofundamento das memórias práticas no contexto do grupo cigano. Embora tenha se utilizado de alguns recursos da etnografia, avaliamos que o procedimento esteve mais voltado para a imersão territorial e contextualização do grupo do que efetivamente para a investigação das memórias práticas. Tendo em vista os resultados encontrados, sugerimos ainda a realização de novos estudos focalizando as relações de gênero e os aspectos intergeracionais para análise da relação entre memória e identidade no contexto sociocultural cigano.

Considerando-se que os ciganos têm sido alvo de preconceitos e de discriminação social ainda na atualidade, defende-se a importância de estudos que auxiliem no processo de ressignificação do pensamento social não cigano, contribuindo para a legitimação da questão cigana e de suas lutas, redução de violências de diferentes ordens contra essa etnia, bem como defesa da cultura e sociabilidade ciganas.

\section{Referências}

Acton, T. H., \& Mundy, G. (1997). Romani Culture and Gypsy Identity, Hertfordshire: University of Hertfordshire Press.

Andrade Júnior, L. (2013). Os ciganos e os processos de exclusão. Revista Brasileira de História, 33(66), 95-112.

Bardin, L. (2002). Análise de conteúdo. Lisboa: Edições 70 .

Batista, R. R., \& Medeiros, M. J. C. (2015). Nomadismo e diáspora: sugestões para se estudar os ciganos. Revista Anthropológicas, 26(1), 201-230.

Blasco, P. G. (2001). 'We don't Know our Descent': how the Gitanos of Jarana Manage the Past. Journal of the Royal Anthropological Institute, 7(4), 631-647.

Bonomo, M., Faria, J. M. G., Souza, L., \& Brasil, J. A. (2012). Temor e fascínio: dimensão afetiva e representações sociais de ciganos entre população não cigana. Psicologia e Saber Social, 1(2), 245-264.

Bossi, E. (2003). O tempo vivo da memória: ensaios de psicologia social. São Paulo: Ateliê Editorial.

Brasil (2013). Secretaria de Políticas de Promoção da Igualdade Racial. Brasil cigano: Relatório Executivo - I Semana Nacional Dos Povos Ciganos, 1-49.

Recuperado de http://www.seppir.gov.br/comunidadestradicionais/relatorio-executivo-brasilcigano.pdf.

Cabecinhas, R. (2006). Identidade e memória social: estudos comparativos em Portugal e em Timor-Leste. In M. Martins, H. Sousa \& R. Cabecinhas (Eds.). Comunicação e lusofonia: para uma abordagem crítica da cultura e dos media (pp. 183-214).

Porto: Centro de Estudos de Comunicação e Sociedade e Campo das Letras.

Camargo, B. V. (2005). Alceste: um programa informático de análise quantitativa de dados textuais. In A. S. P. Moreira, J. C. Jesuíno \& B. V. Camargo (Org.). 
Perspectivas teórico-metodológicas em representações sociais (pp. 511-539). João Pessoa: EdUFPB.

Carvalho, N. C., Lima, M. E. O., Faro, A., \& Silva, C. A. F. (2012). Representações sociais dos ciganos em Sergipe: contato e estereótipos. Psicologia e Saber Social, 1(2), 232-244.

Ceneda, S. (2002). Romani Women from Central and Eastern Europe: a Fourth World', or Experience of Multiple Discrimination. Czech Republic/Poland/Romania: Asylum Aid.

Connerton, P. (1999). Como as sociedades recordam. Oeiras: Celta.

Vaz, A. D. (2009). Geografia e diversidade cultural: territorialização de um grupo cigano em Goiás, Brasil. Cuadernos de Geografía - Revista Colombiana de Geografía, 1(18), 83-97.

Ferrari, F. (2006). Ciganos nacionais. Acta Literária, 1(32), 79-96.

Fonseca, I. (1996). Enterrem-me em pé: a longa viagem dos ciganos. São Paulo: Companhia das Letras.

Frochtengarten, F. (2005). A memória oral no mundo contemporâneo. Estudos Avançados, 19(55), 367-376.

Halbwachs, M. (2006). A memória coletiva. São Paulo: Centauro.

Jedlowski, P. (2001). Memory and Sociology: Themes and Issues. Time \& Society, 10(1), 29-44.

Jedlowski, P. (2005). Memória e a mídia: uma perspectiva sociológica. In C. P. Sá (Org.). Imaginário e representações sociais (pp. 121-164). Rio de Janeiro: Museu da República.

Jovanovi , J., Kóczé, A., \& Balogh, L. (2015). Intersections of Gender, Ethnicity, and Class: History and Future of the Romani Women's Movement. Budapest: Central European University.
Jovchelovitch, S. (2008). Os contextos do saber: Representações, comunidade e cultura. Petrópolis, RJ: Editora Vozes.

Kende, A., Hadarics, M., \& Lášticová, B. (2017). Anti-Roma Attitudes as Expressions of Dominant Social Norms in Eastern Europe. International Journal of Intercultural Relations, 60, 12-27.

Lermo, J., Román, J., Marrodán, M. D., \& Mesa, M. S. (2006). Modelos de distribución de apellidos en la población gitana española. Antropo, 13, 69-87.

Mendes, M. M. (2015). Nos interstícios das sociedades plurais e desigualitárias: a situação social dos ciganos. Escola Superior de Educação de Viseu, 32-41.

Miranda, F. P. F. (2011). Ciganos no documentário brasileiro: imagens do passado refletidas no presente. Revista Panorama, 1(2), 29-42.

Moonen, F. (2011). Anticiganismo: os ciganos na Europa e no Brasil (3a ed. revista e atualizada). Recuperado de http://www.educadores.diaadia.pr.gov.br /arquivos/File/pacto_nacional_em/antic iganismo.pdf.

Nascimento, A. P. A., \& Menandro, P. R. (2005). Reinações de menino: a memória saudosa da infância na música popular brasileira. Memorandum, 9, 9-27.

Nascimento, A. R. A., \& Menandro, P. R. M. (2006). Análise lexical e análise de conteúdo: uma proposta de utilização conjugada. Estudos e Pesquisas em Psicologia, 6(2), 72-88.

Pizzinato, A. (2009). Identidade narrativa: papéis familiares e de gênero na perspectiva de meninas ciganas. Arquivos Brasileiros de Psicologia, 61(1), 38-48.

Pollak, M. (1989). Memória, esquecimento e silêncio. Revista Estudos Históricos, Rio de Janeiro, 2(3), 3-15. Recuperado de http://www.uel.br/cch/cdph/arqtxt/Me moria_esquecimento_silencio.pdf.

Pollak, M. (1992). Memória e identidade social. Revista Estudos Históricos, Rio de Janeiro, 
5(10), 200-212. Recuperado de http://bibliotecadigital.fgv.br/ojs/index.p hp/reh/article/view/1941/1080.

Powell, R., \& Lewer, J. (2017). Europe’s Perennial 'Outsides': a Processual Approach to Roma Stigmatization and Ghettoization. Current Sociology, 65(5), 680-699.

Ravnbøl, C. I. (2010). The Human Rights of Minority Women: Romani Women's Rights from a Perspective on International Human Rights Law and Politics. International Journal on Minority and Group Rights, 17(1), 1-45.

Reinert, M. (1990). Alceste, une methodologie d'analyse des donnees textuelles et une application - Aurelia de Gerard de Nerval. Bulletin de Methodologie Sociologique, 1(26), 24-54.

Sá, C. P. (2005). As memórias da memória social. In C. P. Sá (Org.). Imaginário e representações sociais (pp. 63-86). Rio de Janeiro: Museu da República.

Sá, C. P. (2007). Sobre o campo de estudo da memória social: uma perspectiva psicossocial. Psicologia: Reflexão e Crítica, 20(2), 290-295.

Sá, C. P. (2012). Psicologia social da memória: sobre memórias históricas e memórias geracionais. In A. M. Jaco-Vilela \& L. Sato (Orgs.). Diálogos em Psicologia Social (pp. 46-57). Rio de Janeiro: Centro Edelstein de pesquisas sociais.

Silva, L. F. (2012). Processo de fixação entre famílias ciganas em Limoeiro do Norte, Ceará: estigma e mudanças socioculturais. Cadernos do LEME, 4(1), 34-46.

Souza, M. R. (2015). Psicologia Social e etnografia: histórico e possibilidades de contato. Psicologia: Ciência e Profissão, 35(2), 389-405.

Stoyanova, S., Doseva, N., Gergov, T., \& Virginás-Tar, E. V. (2015). Nostalgia and Sentimentality among Minority Elderly People (Bulgarian Roma People and Hungarians Living in Romania). Psychological Thaought, 8(1), 82-93.
Teixeira, R. C. (2008). História dos ciganos no Brasil. Recife: Núcleo de Estudos Ciganos.

Valentim, R., Trindade, Z. A., \& Menandro, M. C. S. (2010). Memórias sociais de juventude entre quilombolas do norte do Espírito Santo. Psicologia \& Sociedade, 22(2), 279-287.

Recebido em: 23/1/2018

Aprovado em: 20/2/2019 